\title{
Stress fracture of the distal tibial metaepiphysis as a rare complication of interlocking intramedullary nailing
}

\author{
M.S. Krivorotko, S.S. Rodionova, Yu.V. Buklemishev \\ National Medical Research Center of Traumatology and Orthopedics n.a. N.N. Priorov, Moscow, Russian Federation
}

\begin{abstract}
Introduction This article describes a clinical case of a stress fracture of the distal tibial metaepiphysis following a high-energy tibial shaft fracture stabilized with interlocking intramedullary (IM) nail to identify an underlying cause of the traumatic event. Objective To demonstrate the occurrence of a stress fracture after adequate interlocking IM nailing of a traumatic fracture due to systemic osteoporosis that presented no clinical manifestations prior to injury. Material and methods Magnetic resonance imaging was performed to diagnose the stress fracture. Bone mineral density and laboratory markers of bone metabolism were measured to identify underlying causes of the stress fracture. Consolidation of the traumatic fracture fixed with interlocking IM nail was re-evaluated with a radiograph of the fracture site. Results The stress fracture was seen off the IM nail on MRI scans. Osteoporosis was diagnosed with bone densitometry using dual energy X-ray absorptiometry, and deoxypyridinoline, a bone resorption marker and vitamin D deficiency were identified with laboratory tests. No signs of fracture union were seen radiologically. Conclusion A stress fracture of the distal tibial metaepiphysis detected 3 months after a tibial shaft fracture fixed with interlocking IM nail can be considered an insufficiency fracture caused by primary (idiopathic) systemic osteoporosis that was asymptomatic prior to the high-energy injury.

Keywords: osteoporosis, fracture, intramedullary nailing, alfacalcidol, stress fracture
\end{abstract}

\section{BACKGROUND}

Interlocking intramedullary (IM) nailing is widely recognized as the treatment of choice for most tibia and femur fractures. Stress fractures as an uncommon complication have been described in osteosynthesis of the femur [1]. We have not encountered reports on the complication in fractures of tibia. Stress fractures of tibia without previous trauma are common injuries in athletes and military recruits, and in its most inclusive description [2] include both fatigue and insufficiency fractures. In earlier publications [3] femoral stress fractures following interlocking IM nailing are linked to surgical errors and several predisposing factors and medical conditions that may contribute to the development of stress fractures. We report a clinical case of a stress fracture of the distal tibial metaepiphysis following a traumatic tibial fracture stabilized with interlocking intramedullary (IM) nail in a patient with systemic osteoporosis that was asymptomatic prior to injury.

Objective To demonstrate the occurrence of a stress fracture after adequate interlocking IM nailing of a traumatic fracture due to systemic osteoporosis that presented no clinical manifestations prior to injury.

\section{MATERIAL AND METHODS}

A 43-year-old male with a history of mountain skiing injury since 3 months (04.08.2019) presented to the NMRC TO with pain and swelling over the left ankle. He was then diagnosed with closed comminuted tibia fracture on the left at the boundary of the mid and lower thirds (Fig. 1) that was stabilized with interlocking IM nail (DePuy Synthes Expert) on 07.08.2019. He was recommended to use two crutches for two months postoperatively and gradually increase weight-bearing on the involved leg. However, the patient started using a cane at his own will at one month despite persistent pain at the fracture site and the gastrocnemius. Two weeks later, he started using crutches again due to aggravating pain along the tibia. Radiograph of the fracture (Fig. 2) was produced two months later at the place where surgery was performed. Bone realignment was rated as satisfactory. The persistent edema of the tibia and the ankle, gastrocnemius pain were neglected. Three months later, he presented to the NMRC TO with pain and swelling over the ankle. Physical examination revealed a man of regular build, $185 \mathrm{~cm}$ tall, $80 \mathrm{~kg}$ body weight, BMI of $23.37 \mathrm{~kg} / \mathrm{m}^{2}$, an absolute length of the left lower limb (fracture side) measuring $1 \mathrm{~cm}$ less than that of the right lower limb. He presented with moderate swelling over the left ankle with the circumference of the left ankle measuring $240 \mathrm{~mm}$ while the right ankle was $215 \mathrm{~mm}$. He had no changes in the ROM and experienced pain at the extreme flexion and extension. 


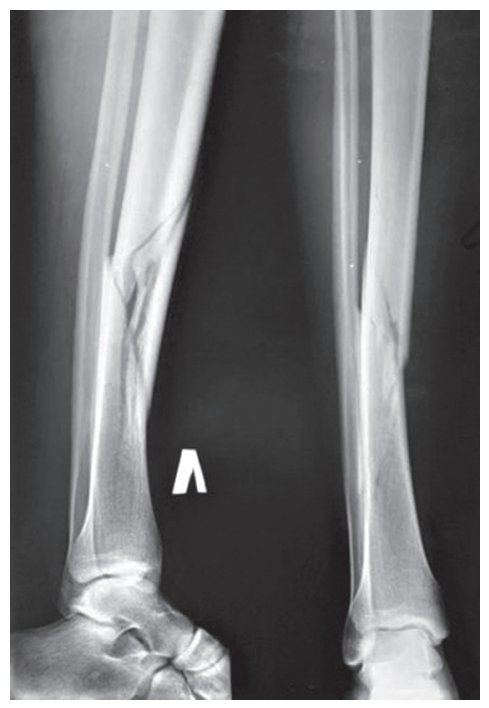

Fig. 1 Preoperative radiographs showing comminuted tibia fracture on the left at the boundary of the mid and lower thirds

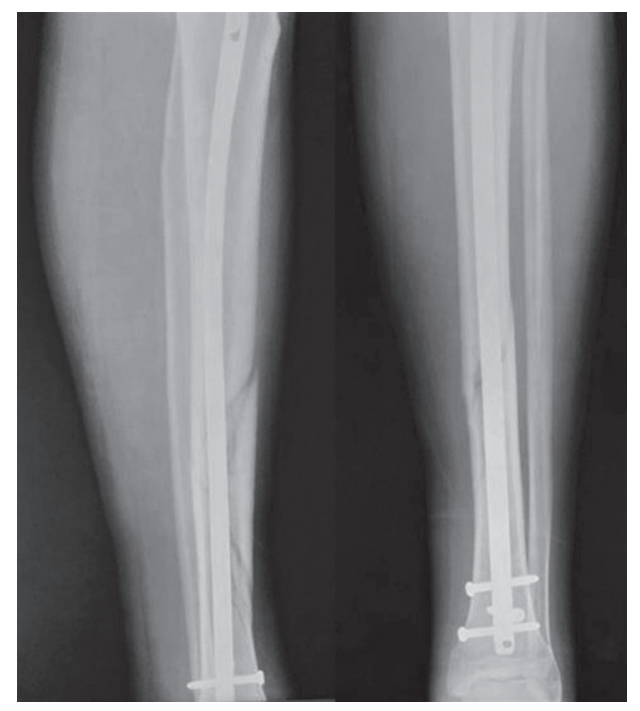

Fig. 2 Radiographs performed at 2 months following operative treatment showing satisfactory bone realignment and no union

\section{RESULTS}

Radiographs produced on admission (Fig. 3) showed a clear fracture line, weak consolidation and a horizontal rarefaction in the distal metaepiphysis below the nail (Fig. 3) that was identified as a stress fracture.

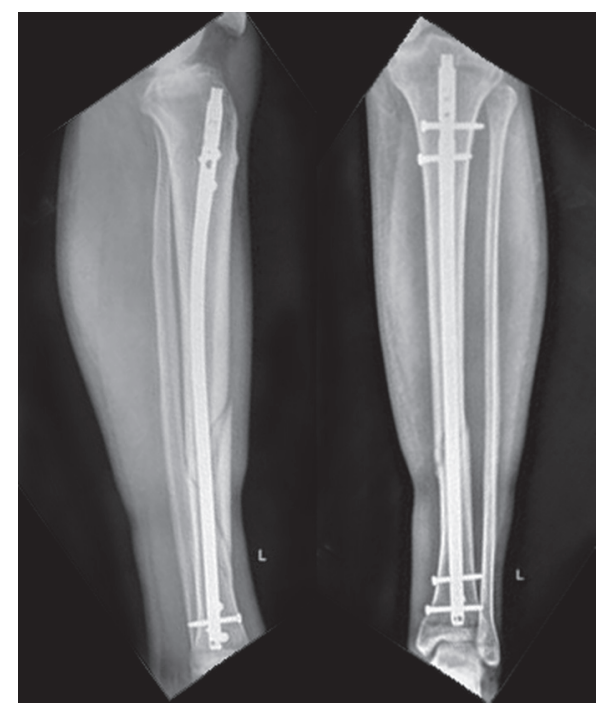

Fig. 3 Radiographs of tibia produced on the day the patient presented to the NMRC TO at 3-month follow-up. No signs of fracture union seen, rerafaction area detected at the distal metaepiphysis

With the radiological signs of delayed consolidation dynamization of the nail with the removal of the proximal screw on 18.11.2019 was recommended for the patient along with MRI examination to verify the stress fracture at the distal metaepiphysis. MRI showed linear hypointense signal on the T1W images (Fig. 4) and hyperintense signal on STIR W images (Fig. 4) at the boundary of the tibial metaphysis and epiphysis (more laterally). The condition was diagnosed as initial stage of the stress fracture of the lateral aspect of the distal tibia.

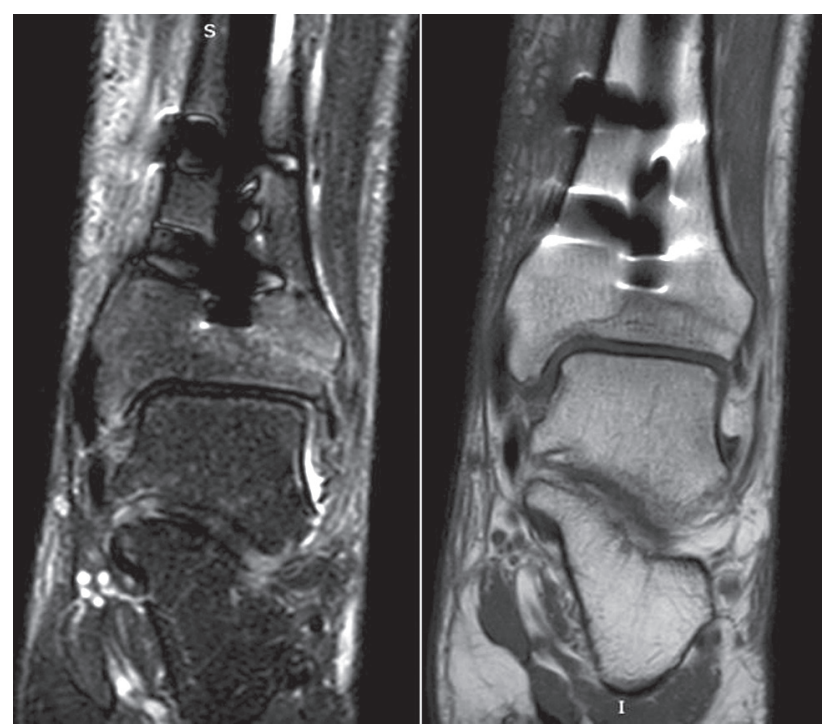

Fig. 4 MRI scans of the ankle joint showing linear hypointense signal on the T1W images (on the right) and hyperintense signal on STIR W images at the boundary of the tibial metaphysis and the epiphysis (on the left)

Bone densitometry using dual energy X-ray absorptiometry (DEXA) and laboratory tests were additionally performed for the patient to identify the underlying cause of the stress fracture, evaluate calcium phosphorus metabolism and bone remodeling markers. DEXA measurements showed maximal loss of bone mineral density (BMD) measuring $-2.5 \mathrm{SD}$ in the lumbar spine with the use of Z-scores and was less evident in the femoral neck (Table 1) and appeared to be prevalent at the fracture side. Based of the measurements and the metaepiphyseal fracture being unrelated to an injury the condition was diagnosed as osteoporosis. Elevated urinary bone resorption markers (Table 2) could be responsible for osteoporosis (high-speed) and delayed union of traumatic fracture [4]. 
Findings of dual energy X-ray absorptiometry

\begin{tabular}{|c|c|c|c|c|c|}
\hline \multicolumn{2}{|l|}{ Body site } & BMD $\left(\mathrm{g} / \mathrm{cm}^{2}\right)$ & T-scores & Z-scores & $\%$ \\
\hline \multicolumn{2}{|l|}{ L1-L4 } & 1.001 & -1.8 & -1.8 & 82 \\
\hline \multicolumn{2}{|l|}{ L1 } & 0.952 & -1.7 & -1.7 & 82 \\
\hline \multicolumn{2}{|l|}{ L2 } & 1.079 & -1.3 & -1.3 & 87 \\
\hline \multicolumn{2}{|l|}{ L3 } & 1.043 & -1.6 & -1.6 & 84 \\
\hline \multicolumn{2}{|l|}{ L4 } & 0.933 & -2.6 & -2.5 & 75 \\
\hline \multirow{2}{*}{ Left femur } & neck & 0.788 & -2.2 & -1.8 & 74 \\
\hline & overall & 0.847 & -1.9 & -1.6 & 78 \\
\hline \multirow{2}{*}{ Right femur } & neck & 0.909 & -1.2 & -0.9 & 85 \\
\hline & overall & 0.946 & -1.1 & -0.8 & 87 \\
\hline
\end{tabular}

Laboratory tests of the blood and urine

\begin{tabular}{|l|c|c|}
\hline \multicolumn{1}{|c|}{ Parameter } & Value & Reference interval \\
\hline ALP & 77 & $55-149$ \\
\hline $\mathrm{Ca}$ & 2.53 & $2.15-2.55$ \\
\hline $\mathrm{P}$ & 1.02 & $0.81-1.45$ \\
\hline PTH & 33.5 & $15-65$ \\
\hline $\mathrm{OST}$ & 27 & $14-42$ \\
\hline $\mathrm{DPD}$ & 9.06 & $2.3-5.4$ \\
\hline & & $<10-$ deficit \\
\cline { 2 - 3 } 25(OH)D & 23.7 & $10-30-$ lack \\
\cline { 3 - 3 } & & $30-100-$ normal \\
\hline Testosterone & 4.0 & $>100-$ excess \\
\hline Free testosterone & 12.78 & $2.49-8.36$ \\
\hline Sex hormone binding globulin & 29 & $4.5-42.00$ \\
\hline Luteinizing hormone & 6.1 & $13-71$ \\
\hline Follicle-stimulating hormone & 3.28 & $1.7-8.6$ \\
\hline Prolactin & 13.8 & $1.5-12.4$ \\
\hline
\end{tabular}

Osteoporosis was diagnosed as primary idiopathic in the patient with no disease being capable to affect bone metabolism detected in the patient and hypogonadism ruled out with sex hormones tests. Delayed union of the tibial shaft fracture and the development of the stress fracture (insufficiency fracture) distal off the IM nail were considered as complications of primary osteoporosis that was asymptomatic prior to injury. Alfacalcidol and calcium drugs were administered to treat osteoporosis in addition to the limb unloading.

\section{DISCUSSION}

Stress fractures are a common entity encountered in professional athletes and military recruits [2]. Stress fractures include fatique fractures that occur as a result of repetitive forces on normal bone, whereas insufficiency fractures occur in structurally abnormal bone [5].

Persons who participate in repetitive, highintensity training, such as athletes and military recruits, are at increased risk of developing fatigue fractures. Repetitive and excessive stress on the bone leas to a specific pathophysiological 'loop' of increasing microfractures of bone trabeculae. The production of microfractures caused by insufficient time for the bone to repair invokes osteocyte apoptosis recruiting osteoclasts to initiate bone resorption, cortical porosity decreasing bone strength that can result in a stress injury with minimal trauma involved or without it [6].

Stress fractures termed as insufficiency fractures were described to occur in patients with osteomalacia [7], osteogenesis imperfecta [8], osteoporosis [9].

Insufficiency fractures are the result of normal loading upon abnormally weakened bone. Osteocyte lacunae demonstrate increased mineralization [10] and sensitivity to mechanical stress in patients diagnosed with primary or secondary osteoporosis. Increased activation of bone remodeling in osteoporotic patients favoring bone resorption ultimately decrease bone strength [11].

We have not encountered reports on stress fractures following IM nailing of tibia in the existing 
literature and have identified several factors causing stress injuries in our case:

- the nail as a stress riser [12];

- overloaded limb due to violated orthopaedic discipline;

- primarily impaired osseous metabolism (osteoporosis, osteomalacia).

Associated complications after intramedullary nailing of tibial shaft fracture include nail-specific pains due to patellofemoral arthritis in suprapatellar approach or scars at the patellar ligament attachment in infrapatellar approach or at the fracture site due to the rotational alignment [13]. Our patient experienced pain at the fracture site early after surgery that aggravated at 3 months following dynamization of the construct. He developed ankle pain close or at the site of the stress fracture in a delayed manner that aggravated during the last month. This could be associated with the stress riser causative factor but such clinical cases were reported after interlocking nailing of femur fractures only. The cases [12] included intertrochanteric and supracondylar fractures occurred at the interlocking sites.

The localization of stress fracture in our patient could not imply a stress riser. As to the possible links between the fracture and violated orthopaedic discipline our patient stopped using crutches to unload the limb one month after surgery but aggravated pain made him return to unloading at two weeks. So, increased weight-bearing was short term and re-use of the crutches helped him to improve pain.

Systemic osteoporosis is deemed to play a crucial role in the development of the stress fracture associated with different pathological processes in the bone due to deficient BMD and increased activation of bone remodeling $[14,15]$. The condition resulted in delayed union of traumatic tibial fracture at a threemonth follow-up despite satisfactory bone alignment achieved and construct stability provided for our patient. A poor fracture consolidation in osteoporotic patient is reported to be also attributed to cortical and cancellous bone imbalance with low BMD [16].

Primary osteoporosis has been reported increasingly often in men during the past few years. Although many risk factors contribute to the pathogenesis of osteoporosis no reports describe their particular role in marked reductions in BMD and associated fragile fractures in males. Risk factors that are more likely to be discussed include age, life-style factors such as nicotine abuse, alcohol consumption; variance of peak bone mass due to polymorphisms of genes encoding the vitamin D receptor (VDR) and type I collagen (COL1A1) [17]. Peak bone mass variance as a pediatric problem could be considered as a cause of osteoporosis in out patient due to the absence of apparant risk factors. The condition was found to be a good predictor of osteoporosis at older age [18]. To our knowledge, idiopathic osteoporosis in males are commonly characterized by decrease in bone formation and resorption markers.

Increased bone resorption with a higer level of urinary deoxypyridinoline (DPD) observed in out patient 3 months after surgery could suggest increased activation of bone remodeling with resorption prevailing over bone formation. DPD represents collagen cross-links hydroxypyridinium that breaks down as a result of bone resorption and is excreted into the circulation and urine. The marker is highly specific for bone tissue with increased concentrations indicating to very intense resorption [19]. The elevated concentrations of the marker can be also associated with tibial fracture surgical repair, and the bone resorption marker was reported to be slowly elevating within 4 months after fracture [4].

The differences in BMD loss in the femoral neck (exceeding by DXA error and was more evident on the left as compared to the right) could be caused by long-term unloading of the left lower limb. Immobilization is known to result in $1 \%$ decrease in BMD without vitamin D and calcium supplementation [20]. Osteoporosis could cause delayed consolidation of tibial fracture stabilized with interlocking nailing. Stress fractures without history of trauma and tibial nailing were reported in patients with primary and secondary osteoporosis [21].

Clinical evidence suggests that sufficient amounts of calcium are required for fracturecallus mineralisation, compromised bone repair in osteoporotic patient using cholecalciferol/alfacalcidol [22]. Alfacalcidol combined with calcium drugs were administered for the patient. Alfacalcidol can be used to treat osteoporosis. The use of alfacalcidol to treat primary osteoporosis in males relies on the effect of the drug inducing both remodeling processes depending on a situation. In our clinical scenario, the drug was administered to exert an anabolic effect. Alfacalcidol was experimentally shown to contribute to bone formation [23]. The authors reported in vivo suppression effect of alfacalcidol on bone resorption maintaining and stimulating bone formation at the same time. Iliac crest biopsies histomorphometrically examined before and after alfacalcidol treatment showed increased cancellous and cortical mass in males with idiopathic osteoporosis [24]. 


\section{CONCLUSION}

A stress fracture of the distal tibial metaepiphysis detected 3 months after a tibial shaft fracture fixed with interlocking IM nail can be considered an insufficiency fracture caused by primary (idiopathic) systemic osteoporosis that was asymptomatic prior to the highenergy injury. A metabolic stress-like condition caused by a traumatic injury in osteoporotic patient can result in delayed bone union and a stress/insufficency fracture.

\section{REFERENCES}

1. Daner W.E. III, Owen J.R., Wayne J.S., Graves R.B., Willis M.C. Jr. Biomechanical evaluation of the risk of secondary fracture around short versus long cephalomedullary nails. Eur. J. Orthop. Surg. Traumatol., 2017, vol. 27, no. 8, pp. 11031108. DOI: 10.1007/s00590-017-1989-6

2. Patel D.S., Roth M., Kapil N. Stress fractures: diagnosis, treatment, and prevention. Am. Fam. Physician, 2011, vol. 83, no. 1, pp. 39-46.

3. Beals R.K., Tower S.S. Periprosthetic fractures of the femur. An analysis of 93 fractures. Clin. Orthop. Relat. Res., 1996, no. 327, pp. 238-246. DOI: 10.1097/00003086-199606000-00029

4. Ivaska K.K., Gerdhem P., Akesson K., Garnero P., Obrant K.J. Effect of fracture on bone turnover markers: a longitudinal study comparing marker levels before and after injury in 113 elderly women. J. Bone Miner. Res., 2007, vol. 22, no. 8, pp. 1155-1164. DOI: 10.1359/jbmr.070505

5. Matcuk G.R. Jr., Mahanty S.R., Skalski M.R., Patel D.B., White E.A., Gottsegen C.J. Stress fractures: pathophysiology, clinical presentation, imaging features, and treatment options. Emerg. Radiol., 2016, vol. 23, no. 4, pp. 365-375. DOI: 10.1007/ s10140-016-1390-5

6. Hughes J.M., Popp K.L., Yanovich R., Bouxsein M.L., Matheny R.W. Jr. The role of adaptive bone formation in the etiology of stress fracture. Exp. Biol. Med. (Maywood), 2017, vol. 242, no. 9, pp. 897-906. DOI: 10.1177/1535370216661646

7. Kobayashi H., Ito N., Akiyama T., Okuma T., Kinoshita Y., Ikegami M., Shinoda Y., Fukumoto S., Tanaka S., Kawano H. Prevalence and clinical outcomes of hip fractures and subchondral insufficiency fractures of the femoral head in patients with tumour-induced osteomalacia. Int. Orthop., 2017, vol. 41, no. 12, pp. 2597-2603. DOI: 10.1007/s00264-017-3610-3

8. Iwata K., Mashiba T., Shimamura M., Miki T., Yamamoto T. Accumulation of microdamage and low bone mass in the femoral head as a cause of subchondral insufficiency fracture in a patient with osteogenesis imperfecta. J. Bone Miner. Metab., 2019, vol. 37, no. 5, pp. 768-772. DOI: 10.1007/s00774-019-01006-y

9. Spiegl U.J.A., Schnake K.J., Osterhoff G., Scheyerer M.J., Ullrich B., Bula P., Siekmann H. Imaging of Sacral Stress and Insufficiency Fractures. Z. Orthop. Unfall., 2019, vol. 157, no. 2, pp. 144-153. DOI: 10.1055/a-0640-8933

10. Carpentier V.T., Wong J., Yeap Y., Gan C., Sutton-Smith P., Badiei A., Fazzalari N.L., Kuliwaba J.S. Increased proportion of hypermineralized osteocyte lacunae in osteoporotic and osteoarthritic human trabecular bone: implications for bone remodeling. Bone, 2012, vol. 50, no. 3, pp. 688-694. DOI: 10.1016/j.bone.2011.11.021

11. Marques E.A., Gudnason V., Sigurdsson G., Lang T., Johannesdottir F., Siggeirsdottir K., Launer L., Eiriksdottir G., Harris T.B. Are bone turnover markers associated with volumetric bone density, size, and strength in older men and women? The AGES-Reykjavik Study. Osteoporos. Int., 2016, vol. 27, no. 5, pp. 1765-1776. DOI: 10.1007/s00198-015-3442-1

12. Brumback R.J., Ellison T.S., Poka A., Bathon G.H., Burgess A.R. Intramedullary nailing of femoral shaft fractures. Part III: Long-term effects of static interlocking fixation. J. Bone Joint Surg. Am., 1992, vol. 74, no. 1, pp. 106-112.

13. Erin-Madsen N., Aasvang T.K., Viberg B., Bloch T., Brix M., Tengberg P.T. Knee pain and associated complications after intramedullary nailing of tibial shaft fracture. Dan. Med. J., 2019, vol. 66, no. 8, pp. A5554.

14. Morozov A.K., Rodionova S.S., Kolondaev A.F., Makarov M.A., Gavriushenko N.S. Znachenie mineralnoi plotnosti i pokazatelei kachestva kostnoi tkani v obespechenii ee prochnosti pri osteoporoze [The value of mineral bone density and quality measurements of bone tissue in ensuring its strength in osteoporosis]. Vestnik Travmatologii i Ortopedii im. N.N. Priorova, 2001, no. 2, pp. 76-80. (in Russian)

15. Schwartz A.V., Nevitt M.C., Brown B.W. Jr., Kelsey J.L. Increased falling as a risk factor for fracture among older women: the study of osteoporotic fractures. Am. J. Epidemiol., 2005, vol. 161, no. 2, pp. 180-185. DOI: 10.1093/aje/kwi023

16. Seebeck J., Goldhahn J., Städele H., Messmer P., Morlock M.M., Schneider E. Effect of cortical thickness and cancellous bone density on the holding strength of internal fixator screws. J. Orthop. Res., 2004, vol. 22, no. 6, pp. $1237-1242$. DOI: 10.1016/j.orthres.2004.04.001

17. Ding Z., Chen Y., Xu Y., Zhou X., Xu Y., Ma Z., Sun Y. Impact of Age, Gender, and Body Composition on Bone Quality in an Adult Population From the Middle Areas of China. J. Clin. Densitom., 2018, vol. 21, no. 1, pp. 83-90. DOI: 10.1016/j. jocd.2016.11.001

18. Lim J.S. Pediatric dual-energy X-ray absorptiometry: interpretation and clinical and research application. Korean J. Pediatr., 2010, vol. 53, no. 3, pp. 286-293. DOI: 10.3345/kjp.2010.53.3.286

19. Pobel E.A., Bengus L.M., Dedukh N.V. Markery kostnogo metabolizma pri srashchenii perelomov dlinnykh kostei [Bone metabolism markers when healing long bone fractures]. Osteoporoz i Osteopatii, 2012, vol. 15, no. 2, pp. 25-32. (in Russian)

20. Deliagin V.M. Snizhenie kostnoi plotnosti v raznye vozrastnye periody (mnogogrannost problemy) [Bone density reducing in different age-related periods (versatility of the problem)]. Meditsinskii Sovet, 2012, no. 2, pp. 94-99. (in Russian)

21. Miyakoshi N., Sato K., Murai H., Tamura Y. Insufficiency fractures of the distal tibiae. J. Orthop. Sci., 2000, vol. 5, no. 1, pp. 71-74. DOI: 10.1007/s007760050011

22. Patologicheskie perelomy, oslozhniaiushchie osteoporoz. MKB 10: M80.1/M80.2/M80.3/M80.4/M80.5/M80.8/M80.9: klin. rek.: (utv. Minzdravom Rossii). 2018 (peresmotr kazhdye 3 goda) [Pathological fractures complicating osteoporosis. MKB 10: M80.1/M80.2/M80.3/M80.4/M80.5/M80.8/M80.9: Clinical Recommendations (approved by the RF Ministry of 
Benij Ortopedii, Vol. 26, no 4, 2020

Health). 2018 (revision every 3 years)]. Available at: https://legalacts.ru/doc/klinicheskie-rekomendatsii-patologicheskieperelomy-oslozhnjaiushchie-osteoporoz-utv-minzdravom-rossii/ (in Russian)

23. Shiraishi A., Takeda S., Masaki T., Higuchi Y., Uchiyama Y., Kubodera N., Sato K., Ikeda K., Nakamura T., Matsumoto T., Ogata E. Alfacalcidol inhibits bone resorption and stimulates formation in an ovariectomized rat model of osteoporosis: distinct actions from estrogen. J. Bone Miner. Res., 2000, vol. 15, no. 4, pp. 770-779. DOI: 10.1359/jbmr.2000.15.4.770

24. Rodionova S.S., Kolondaev A.F., Mukhina L.I. Three years results of alfacalcidol use in patients with osteoporosis. Osteoporosis Inter., 1998, vol. 8, no. Suppl. 3.

Received: 28.01.2020

\section{Information about the authors:}

1. Mikhail S. Krivorotko, M.D.,

National Medical Research Center of Traumatology and Orthopedics n.a. N.N. Priorov, Moscow, Russian Federation

2. Svetlana S. Rodionova, M.D., Ph.D., Professor,

National Medical Research Center of Traumatology and Orthopedics n.a. N.N. Priorov, Moscow, Russian Federation, Email: rod06@inbox.ru

3. Yuri V. Buklemishev, M.D.,

National Medical Research Center of Traumatology and Orthopedics n.a. N.N. Priorov, Moscow, Russian Federation 